\title{
Characterization of polarity development through 2- and 3-D imaging during the initial phase of microspore embryogenesis in Brassica napus $\mathrm{L}$
}

\author{
Ewa Dubas • Jan Custers $\cdot$ Henk Kieft • \\ Maria Wẹdzony • André A. M. van Lammeren
}

Received: 3 April 2013 / Accepted: 9 July 2013 / Published online: 10 August 2013

(C) The Author(s) 2013. This article is published with open access at Springerlink.com

\begin{abstract}
Isolated microspores of B. napus in culture change their developmental pathway from gametophytic to sporophytic and form embryo-like structures (ELS) upon prolonged heat shock treatment $\left(5\right.$ days at $\left.32^{\circ} \mathrm{C}\right)$. ELS express polarity during the initial days of endosporic development. In this study, we focussed on the analysis of polarity development of ELS without suspensor. Fluorescence microscopy and 3-D confocal laser scanning microscopy (CLSM) without tissue interfering enabled us to get a good insight in the distribution of nuclei, mitochondria and endoplasmic reticulum (ER), the architecture of microtubular (MT) cytoskeleton and the places of 5-bromo2 '-deoxy-uridine (BrdU) incorporation in successive stages of
\end{abstract}

\section{Handling Editor: Pavla Binarova}

Key message A better understanding of androgenesis with a focus on early structural polarization: nuclei mitochondria, ER, MT cytoskeleton and BrdU incorporation. SEM revealed presence of ECM-like structure in androgenic embryos.

Electronic supplementary material The online version of this article (doi:10.1007/s00709-013-0530-y) contains supplementary material, which is available to authorized users.

H. Kieft · A. A. M. van Lammeren

Laboratory for Cell Biology, Wageningen University and Research

Centre, Droevendaalsesteeg 1, Radix building 107,

W1 6708 PB Wageningen, The Netherlands

\section{J. Custers}

Plant Research International, Wageningen University and Research

Centre, Droevendaalsesteeg 1,

6708 PB Wageningen, The Netherlands

E. Dubas $(\bowtie) \cdot M$. Wędzony

The Franciszek Górski Institute of Plant Physiology, Polish

Academy of Sciences, Niezapominajek 21, 30-239 Kraków, Poland

e-mail: edubas@o2.pl

M. Wędzony

Pedagogical University of Kraków, Podchorążych 2,

30-084 Kraków, Poland microspore embryogenesis. Scanning electron microscopy (SEM) analysis revealed, for the first time, the appearance of a fibrillar extracellular matrix-like structure (ECM-like structure) in androgenic embryos without suspensor. Two types of endosporic development were distinguished based upon the initial location of the microspore nucleus. The polarity of dividing and growing cells was recognized by the differential distributions of organelles, by the organization of the MT cytoskeleton and by the visualization of DNA synthesis in the cell cycle. The directional location of nuclei, ER, mitochondria and starch grains in relation to the MTs configurations were early polarity indicators. Both exine rupture and ECMlike structure on the outer surfaces of ELS are supposed to stabilize ELS's morphological polarity. As the role of cell polarity during early endosporic microspore embryogenesis in apical-basal cell fate determination remains unclear, microspore culture system provides a powerful in vitro tool for studying the developmental processes that take place during the earliest stages of plant embryogenesis.

Keywords Brassica napus · Extracellular matrix-like structure $\cdot$ Microspore embryogenesis $\cdot$ Microtubular cytoskeleton $\cdot$ Nuclear DNA synthesis $\cdot$ Polarity

$\begin{array}{ll}\text { Abbreviations } \\ \text { BrdU } & \text { 5-Bromo-2'-deoxy-uridine } \\ \text { CPD } & \text { Critical point drying } \\ \text { CLSM } & \text { Confocal laser scanning microscopy } \\ \text { CMTs } & \text { Cortical microtubules } \\ \text { 2-D } & \text { Two-dimensional } \\ \text { 3-D } & \text { Three-dimensional } \\ \text { DIC } & \text { Differential interference contrast } \\ \text { DAPI } & \text { 4',6-Diamidino-2-phenylindole } \times 2 \mathrm{HCl} \\ \text { DiOC } & \text { 3,3-Dihexyloxacarbocyanine iodide } \\ \text { DNA } & \text { Deoxyribonucleic acid } \\ \text { DH } & \text { Doubled haploid }\end{array}$




$\begin{array}{ll}\text { ECM } & \text { Extracellular matrix } \\ \text { ELS } & \text { Embryo-like structure } \\ \text { ER } & \text { Endoplasmic reticulum } \\ \text { I/KI } & \text { Iodine/potassium iodide } \\ \text { MTs } & \text { Microtubules } \\ \text { NLN-13 } & \text { Lichter medium } \\ \text { PI } & \text { Propidium iodide } \\ \text { PPB } & \text { Preprophase band } \\ \text { SEM } & \text { Scanning electron microscopy }\end{array}$

\section{Introduction}

Microspore embryogenesis, also called androgenesis, is an intriguing developmental process, in which male gametophytic cells are triggered to sporophytic development, resulting in the production of haploid/doubled haploid (DH) plants (Smýkal 2000; Wędzony et al. 2009). DHs are of high value in basic research as well as in commercial application in plant breeding (Forster et al. 2007; Wędzony et al. 2013). Rapeseed (Brassica napus) is considered as one of the most responsive species in androgenesis (Ferrie 2003) and is a regularly used model system in research on the biological background of the process (Seguí-Simarro and Nuez 2008; Supena et al. 2008; Tang et al. 2013). Since the 1980s, the B. napus microspore embryogenesis system has been intensively studied in many disciplines, on the physiological, biochemical, cytological and molecular levels. Numerous papers described endogenous and exogenous factors affecting the developmental fate of B. napus microspores in culture (Custers 2003; Ferrie 2003; Malik et al. 2008). A rather long heat treatment in the range of $32-40{ }^{\circ} \mathrm{C}$ effectively induces $B$. napus microspores or pollen to initiate androgenic development and embryo formation (Pechan and Keller 1988; Telmer et al. 1992; Binarova et al. 1997; Custers et al. 1994; Joosen et al. 2007; Supena et al. 2008; Dubas et al. 2011). During the induction period, changes in expression of genes and proteins (Cordewener et al. 1995, 2000; Boutilier et al. 2002; Malik et al. 2008), nuclear DNA synthesis (Binarova et al. 1993, 1997) and cytoskeleton aberrations (Hause et al. 1993; Simmonds 1994; Simmonds and Keller 1999) were observed.

B. napus androgenic embryos are commonly used as an alternative to the study of zygotic embryogenesis. Mild heat stress-induced microspore embryogenesis is the most powerful androgenic pathway to produce embryos with established polarity (Supena et al. 2008; Dubas et al. 2011). However, the procedure to obtain embryos mimicking zygotic embryos with suspensor in a big scale is limited to the DH 4079 line derived from B. napus Topas. For a wider range of plant species, only the long-term heat-induced 'classical' microspore embryogenesis could be applied, and it was used extensively (Zaki and Dickinson 1990, 1991; Binarova et al. 1993; Hause et al. 1993; Simmonds and Keller 1999; Custers 2003). Therefore, we investigated the classical system to collect more information about the induction of microspore embryogenesis under prolonged heat stress and focussed on the cytological aspects. We analyzed the process of androgenic embryo development in cases where structures resembling suspensors were absent. We took advantage of the easy access to huge numbers of embryos and the manipulation options using the 'whole mount' immunocytochemical technology for 3-D visualization of the MT cytoskeleton and spatial distribution of cell divisions.

22The induction of microspore embryogenesis involves a set of profound changes in cell morphology (Custers 2003), in cell cycle (Binarova et al. 1993), in the pattern of cytokinesis (Gervais et al. 2000), cytoskeletal configurations (Simmonds and Keller 1999) and new cell wall formation (Simmonds and Keller 1999). Changes in the cytoskeleton as a cell polarity key factor altered polarity of dividing and growing cells (Wasteneys and Galway 2003). When the nucleus moved to the cell centre, the large vacuole fragmented, metabolic activity changed and the embryogenic development started (Hosp et al. 2007).

Ultrastructural, fluorescence and immunocytochemical studies have shown the significance of symmetrical nuclear division that coincided with rearrangements of the cytoskeleton upon heat stress (Zaki and Dickinson 1990, 1991; Hause et al. 1993; Binarova et al.1993; Dubas et al. 2011) as compared to divisions and cytoskeletal organization observed in control microspores and pollen cultured at $18^{\circ} \mathrm{C}$ (Hause et al. 1993; Dubas et al. 2012) or collected from anthers growing in planta (Hause et al. 1992). As heat-treated microspores prepared to embryogenesis exhibited changes in the cytoskeleton organization (Hause et al. 1993; Simmonds and Keller 1999; Dubas et al. 2011), we analysed the changes in microtubule (MTs) configurations. Although MTs can maintain cell polarity, endoplasmic reticulum (ER), mitochondria and starch grains were investigated in some developmental stages, too, and in addition, this paper focuses on the visualization of sites of nuclear DNA synthesis after the application of 5-bromo-2'-deoxy-uridine (BrdU).

As the extracellular matrix (ECM) is an important modulator of cell polarity and a potential structural marker for embryogenic competence acquisition (Berthiaume et al. 1996; Namasivayam et al. 2006), we were interested in its presence in multicellular embryo-like structure (ELS) at the globular stage. For that reason, scanning electron microscopy (SEM) analysis was performed. We were interested if there is a link between the deposition of the ECM-like structure and stabilization of morphological polarity.

\section{Materials and methods}

\section{Donor plants}

Plants of B. napus L. cv. 'Topas' line DH 4079 were grown year-round under greenhouse conditions at $20 / 18^{\circ} \mathrm{C}$ day/night 
temperature. Additional light (Philips SON-T lamps) was given from mid-September to the end of April, which also served to obtain a photoperiod of $16 \mathrm{~h}$. At the beginning of bolting, the plants were transferred to a growth chamber and kept at $10{ }^{\circ} \mathrm{C}$ with $16 \mathrm{~h}$ illumination provided by 150 $\mu \mathrm{Em}^{-2} \mathrm{~s}^{-1}$ HPI (Philips) lamps. Plants were watered twice a week with $\mathrm{N}: \mathrm{P}: \mathrm{K}=15: 15: 18$ soluble fertilizer. Inflorescences were harvested at least after 2 weeks of cold treatment, and flower buds of $3.1-3.3 \mathrm{~mm}$ in length were used for the microspore isolation.

Microspore isolation and culture

Microspores were isolated following the protocol of Custers (2003) with modifications by Joosen et al. (2007). Microspore suspensions were cultured in incubators (Marius Instruments or ST4/B/40; Industrial Research Institute for Automation and Measurement) at $32{ }^{\circ} \mathrm{C}$ for 5 days continuously, and then transferred to $25^{\circ} \mathrm{C}$ in NLN-13 modified Lichter (1982) medium with $13 \%$ sucrose $(w / v)$, without potato extract and growth regulators in 6-cm Petri dishes. The culture resulted in the development of androgenic ELS.

Progress of microspore development in embryogenic culture was monitored daily from the isolation day to the tenth day of culture, when globular embryos were found. At least 40 microspores or microspore-derived embryos were studied each day of culture.

\section{BrdU labelling}

To analyze DNA synthesis and cell proliferation under embryogenic conditions, a pulse labelling with the thymidine substitute, 5-bromo-2'-deoxy-uridine (BrdU), was applied on the second day of culture. The BrdU labelling solution (RPN201, Amersham Biosciences) was added to the cultures at final dilution of 1:500. Cells were labelled for $24 \mathrm{~h}$ with BrdU, post-incubated in medium without BrdU during the next $24 \mathrm{~h}$ and then fixed. Morphological development of induced microspores was monitored in cultures without BrdU labelling.

All experiments were repeated at least four times.

Immunolocalization of microtubules and places of DNA synthesis

The whole-mount immunolocalization protocol with improved preservation of cell structures and improved penetration of antibodies was according to Friml et al. (2003) modified by Dubas et al. (2011, 2012).

Sample collection, prefixation, fixation, microspore and pollen wall permeabilization to antibodies, washing and incubation with proper antibodies were done manually on hand-made sieves prepared from 'blue' pipette tips $(5 \mathrm{~mm}$ in diameter) with nylon mesh (11 $\mu \mathrm{m}$, Millipore). For immunostaining, the primary monoclonal antibodies [anti- $\alpha$-tubulin clone DM1A raised in mouse, dilution 1:1,000, Sigma T9026, or anti-BrdU (Bromodeoxyuridine) monoclonal antibody, dilution 1:1000, Amersham Bioscience RPN202] as well as the secondary antibody $\mathrm{GaM} / \mathrm{IgG} /$ Alexa 488 (Molecular Probes A-11001, dilution 1:100) were applied. Control experiments were performed by omitting the first antibody. For DNA counterstaining, the samples were incubated in $0.1 \%$ propidium iodide (PI, Sigma-Aldrich, P-4170) for $15 \mathrm{~min}$, washed in PBS and embedded on slides in Citifluorglycerol (Citifluor Ltd. in glycerol, AF2, Enfield Cloisters).

\section{Visualization of cell components}

DAPI (4',6-diamidino-2-phenylindole $\times 2 \mathrm{HCl}$; Sigma-Aldrich, D-9564) was used to visualize chromatin in whole-mount preparations of the suspension culture according to Custers et al. (1994).

Cellulose was visualized with $0.01 \%$ Calcofluor White ST (4,4'-bis [4-anilino-6-bis (2-hydroxyethyl) amino-s-trizin-2ylamino]-2-2'-stilbenedisulfonic acid) (BioChemika, Fluka 18909) in water (absorption $365 \mathrm{~nm}$, emission $420 \mathrm{~nm}$ ) according to Benziman et al. (1980). Mitochondria and ER were shown with $0.0001 \%, \mathrm{DiOC}_{6}$ (3,3-dihexyloxacarbocyanine iodide; Molecular Probes; D-273; absorption $483 \mathrm{~nm}$, emission $501 \mathrm{~nm}$ ) in water (Terasaki 1994).

All the above-mentioned dyes and reagents, i.e. DAPI, PI, Calcofluor White ST or $\mathrm{DiOC}_{6}$, were added directly on the slide to an equal volume of fresh sample of suspension. Slides were kept in a humid chamber in darkness for at least $15 \mathrm{~min}$ before microscopic analysis.

Starch grains were stained with $0.0001 \%$, I/KI (Lugol's solution). To this end, $50 \mu \mathrm{l}$ of $\mathrm{I} / \mathrm{KI}$ solution was added directly to the same volume of fresh sample of microspore suspension culture. Staining was done on microscope slides kept in a humid chamber in darkness for about $15 \mathrm{~min}$ before analysis.

\section{Microscopic observation}

Confocal laser scanning microscopy (CLSM) and fluorescence microscopy were performed with a CELL MAP IC Bio-Rad (Microscience Division, Hemel Hempstead, UK) CLSM, mounted on a Nikon Eclipse TE 2000-S inverted microscope. Fluorescence was examined under filters EX 470-490/DM 510 BA/515 EF (Alexa 488) and EX 510560/DM 580 BA/590 EF (PI). CLSM images were collected by a Kalman averaging of four full scans. Three-dimensional images and $z$-projections of the cells were obtained by collecting a series of approximately $30-60$ optical sections in the $z$-axis, each section $0.5-1 \mu \mathrm{m}$ thick. Images were acquired and processed using software programs, including 
Lasersharp 2000 software (Microscience Division, Hemel Hempstead, UK), Confocal Assistant 4.02 (written by Todd Clark Brelje), CorelDRAW ${ }^{\circledR}$ ESSENTIALS 9.0 and Adobe Photoshop 5.0 (Adobe Systems, Mountain View, CA, USA).

\section{Scanning electron microscopy}

Material for SEM was prefixed in $5 \%$ GA for $2 \mathrm{~h}$ at $4{ }^{\circ} \mathrm{C}$. After rinsing with water, samples were post-fixed with $1 \%$ $\mathrm{OsO}_{4}$ in water for $2 \mathrm{~h}$ and rinsed again. Next to it, material was dehydrated through a graded ethanol series and dried with a CPD $020\left(\mathrm{CO}_{2}\right.$ critical point drying $)$, coated with $3 \mathrm{~nm}$ platinum using an Oxford CT 1500 HF sputter coating unit and finally observed in a system JEOL JSM $6300 \mathrm{~F}$ scanning electron microscope.

\section{Results}

Morphogenesis after long heat shock treatment

When isolated microspores were cultured at $32{ }^{\circ} \mathrm{C}$ during 5 days and then at $25^{\circ} \mathrm{C}$, they underwent structural reorganization and developed to multicellular ELSs (Figs. 1, 2, 3 and 4).

When isolated from anthers, the majority (at least $60 \%$ ) of the microspores were at the late uninucleate stage of development, each having a big central vacuole occupying most of the lumen of the cell, and the nucleus was located close to the exine opposite one of the three colpi (Fig. 1, a, insert). Mitochondria and ER gave strong fluorescence after DiOC $_{6}$ staining, particularly in the vicinity of the nucleus and in the peripheral cytoplasm (Fig. 1, a).

Based on the analysis of organelle distribution and configurations of the MT cytoskeleton within the cell, two pathways of embryogenesis were distinguished. Type I embryos $(60 \%)$, derived from microspores with their nucleus located close to the microspore cell wall (Fig. 1, a insert), and type II embryos (40\%), derived from microspores with a centrally located nucleus (Fig. 1, b, c, insert).

Type II microspores, with 'star-like' internal morphology, had a big fragmented vacuole and cytoplasmic strands passing from the cell centre through the vacuole to the subcortical cytoplasm (Fig. 1, b1, b2, c, insert, Online Resource 1). Mitochondria and ER gave strong fluorescence after DiOC $_{6}$ staining in cytoplasmic strands in both the vicinity of the nucleus and in the peripheral cytoplasm (Fig. 1, c). At that stage of development, a dense network of thick and long bundles of cortical MTs (CMTs) adjacent to the microspore cell wall was observed (Fig. 1, b1): some exhibited parallel arrangements, while other CMTs had no preferential orientation. Numerous endoplasmic MTs (EMTs) were closely associated with the nucleus (Fig. 1, b2).
Fig. 1 Microspores of Brassica napus induced to sporophytic development by prolonged heat stress treatment. $b, e, f, h, k$ show fluorescent MTs; inserts in $c$ and $i, j, l$ show fluorescent DNA as a result of BrdU incorporation or labelling with DAPI. (a) Uni-nucleate microspore on the first day of culture. Mitochondria and ER, stained with $\mathrm{DiOC}_{6}$ (green), are around the nucleus and in the vicinity of the exine. Insert on the right hand shows the nucleus $(N)$ after PI labelling (red). (b1, b2, c) Type II microspore with its nucleus in the cell centre. Insert in b1 on the right hand shows the nucleolus $(\mathrm{Nu})$ after PI labelling (red). (bl) Dense network of thick and long bundles of CMTs in parallel orientation close to the exine. (b2) Multiple EMTs closely associated with the nucleus $(N)$. The same microspore as in b1. (c) Microspore with a big vacuole transected by cytoplasmic strands passing from the cell centre to the cortical cytoplasm. Mitochondria and ER, stained with $\mathrm{DiOC}_{6}$ (green), are around the nucleus and in the vicinity of the exine. Insert on the right hand shows microspore with nucleus $(N)$ in the cell centre. Microspore visualized in differential interference contrast (DIC)/UV light. (d) Type I microspore with its nucleus close to the exine. Microspore with green fluorescent nucleus indicating that it has entered Sphase. DNA synthesis is traced by BrdU incorporation and immunocytochemical labelling with Alexa 488 (green). Insert shows the nucleus $(N)$ after PI labelling $(r e d)$. (e) Dividing microspore with green fluorescent spindle MTs. Note that the orientation of the division plane turned $90^{\circ}$ with respect to non-induced microspores. Insert shows the chromosomes in the equatorial plane after PI labelling. $(f, g)$. 2-Nucleate endosporic structures derived from type I microspores on the second day of culture. $(f)$ Structure with a network of densely packed cortical MTs without preferential orientation. Insert shows two symmetric nuclei $(N)$ located close to exine after PI staining $(r e d)$. $(g l)$ Structure with $\mathrm{DiOC}_{6}$-stained mitochondria and ER in the vicinity of nuclei and in the peripheral cytoplasm. (g2) Structure with symmetric nuclei $(N)$ after PI staining. Insert on the right hand shows the structure in DIC. $(h, i)$ Twocelled type II structure. $(h)$ Structure with long MTs oriented parallel to each other and aligning the plasma membrane in the equatorial plane where the new cell wall will be formed. Insert shows the symmetric position of two spherical nuclei with well visible nucleoli $(\mathrm{Nu})$ after PI staining $(r e d)$. (i) Structure with mitochondria and ER after $\mathrm{DiOC}_{6}$ staining in the peripheral cytoplasm of both cells. Insert on the right hand shows symmetric nuclei $(N)$. An arrow indicates faint fluorescence of cellulose cell wall after Calcofluor White staining. (j) Twonucleate endosporic structure in which one nucleus entered S-phase. Visualization of DNA synthesis (in green) by BrdU incorporation and immunocytochemical labelling with Alexa 488. The second nucleus is not stained and located below; only the nucleoli are visible (arrows). Insert on the right hand shows the structure in DIC. $(k 1, k 2)$ Threecelled structure with one dividing nucleus within the exine. $(k l)$ Spindle MTs are only observed at the right hand side of the structure and demonstrates asynchronous division. $(k 2)$ The same structure as on $\mathrm{k} 1$ after PI staining. Note chromosomes (arrow) and nuclei $(N)$ simultaneously. (l) 4-Nucleate structure still enclosed in the exine visualized in $\mathrm{DIC} / \mathrm{UV}$ on the fourth day of culture. Insert on the right hand shows the mitochondria and $\mathrm{ER}$ after $\mathrm{DiOC}_{6}$ staining in the vicinity of nuclei and in the peripheral cytoplasm close to the sporoderm. Bar $=20 \mu \mathrm{m}$

The nucleus, derived from type I microspore, often remained close to the exine, when it entered S-phase (Fig. 1, d). Opposite in type II microspores, the S-phase-entered nucleus was located centrally which resulted in similar, central position of mitotic chromosomes (Fig. 1, e insert). The first cell divisions were endosporic, symmetric and proceeded from the second day of culture onwards. In both types of microspores (type I and type II), the symmetry of division did not depend on the initial 

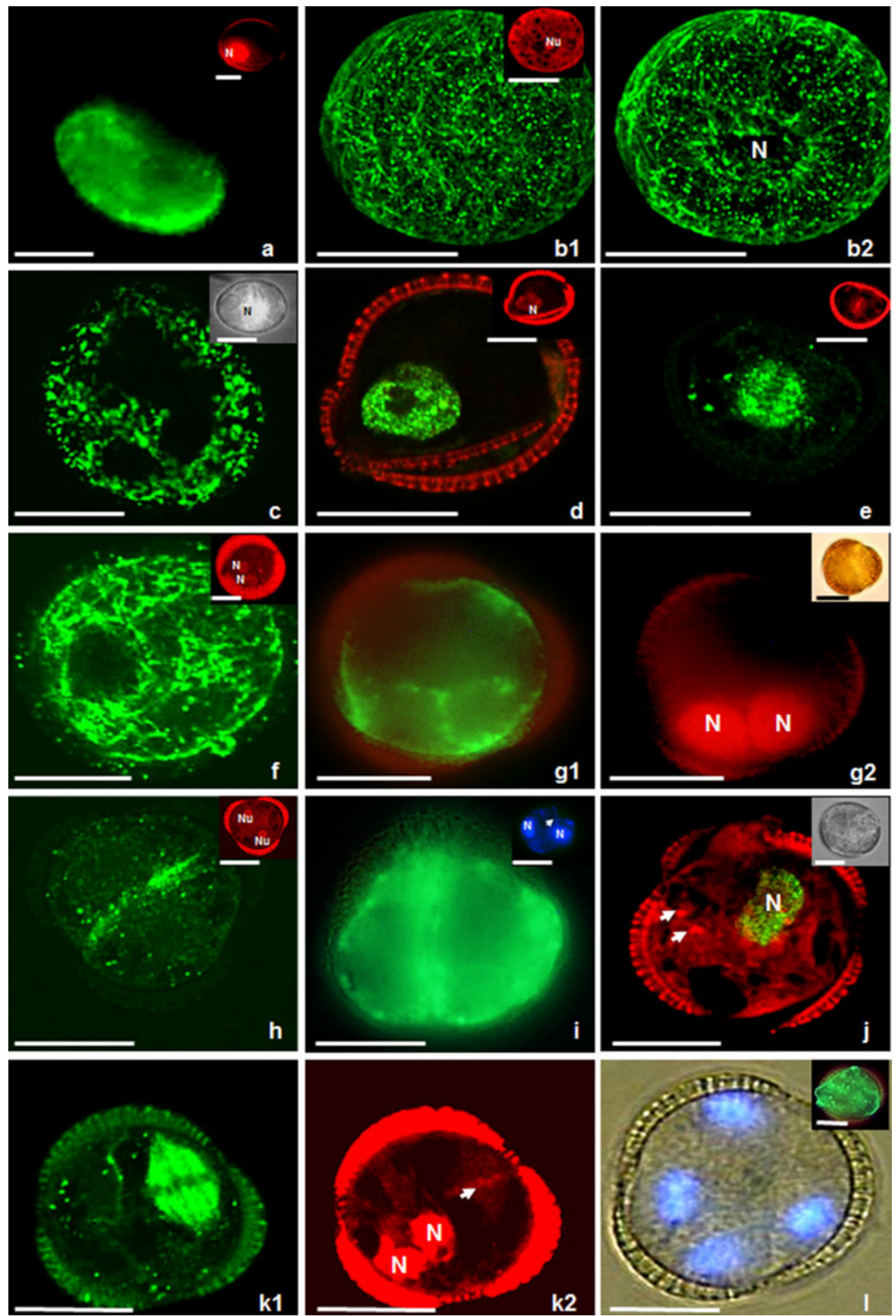

nuclear position. The orientation of the division plane turned $90^{\circ}$ (Fig. 1, e), compared to the orientation that was observed in pollen cultured in vitro at $18{ }^{\circ} \mathrm{C}$ (Dubas et al. 2012) in the case of type I microspores. MTs formed a mitotic spindle with poleto-pole MTs and chromosomes-to-pole MTs (Fig. 1, e, insert).

After the first mitosis, again the distribution of mitochondria and ER and the configuration of MTs differed between type I and type II embryos. In type I, two-nucleate embryos, mitochondria and ER gave strong fluorescence after $\mathrm{DiOC}_{6}$ staining in the vicinity of nuclei and in the peripheral cytoplasm (Fig. 1, g1, g2, insert). Moreover, MTs were not observed at the equatorial plane of cell division, and cellulose cell wall was not detected either. In the sub-cortical layer of these structures, MTs formed a dense network without 

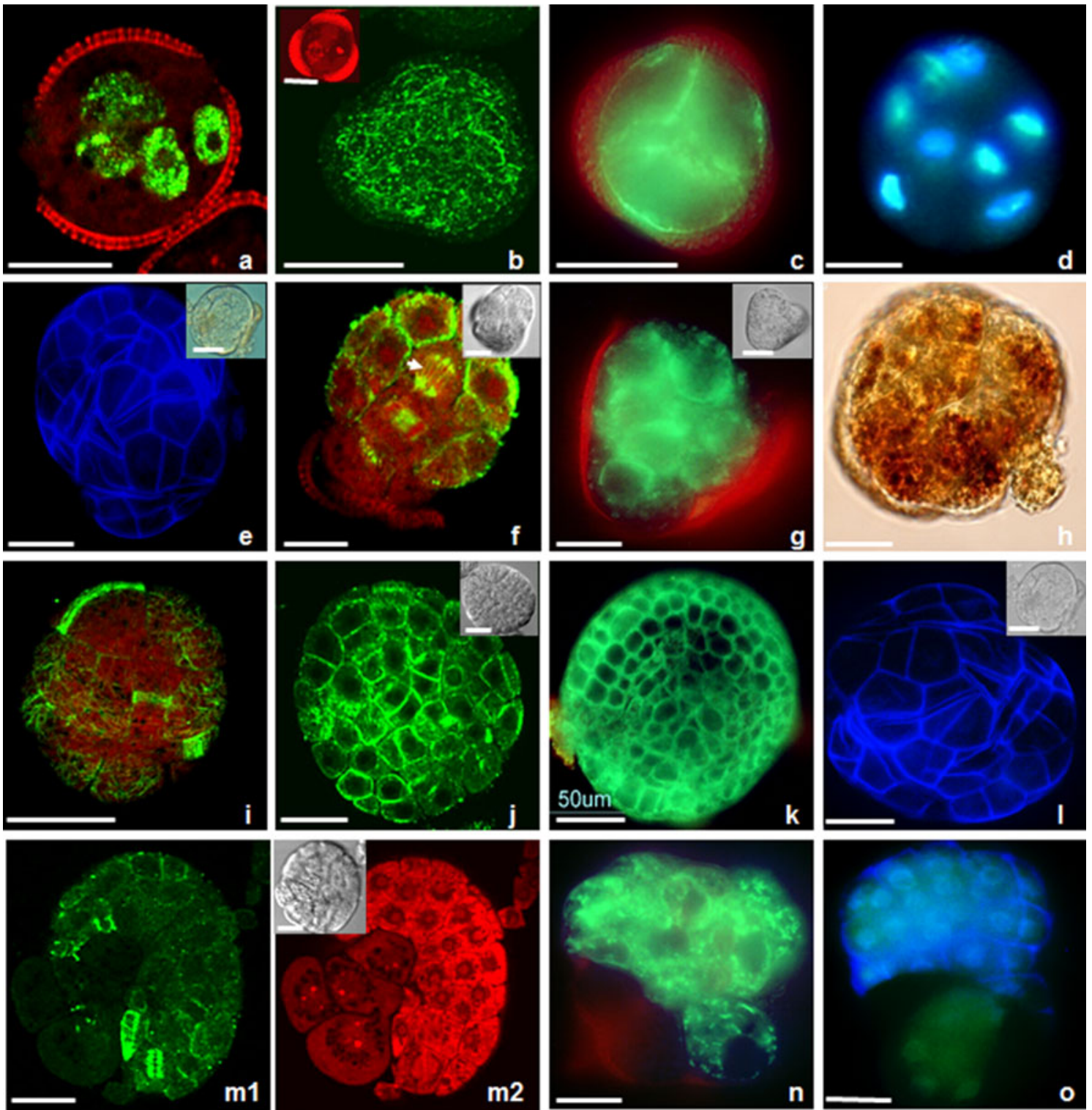

Fig. 2 Morphogenesis of Brassica napus ELS. $b, f, i, j, m$ show fluorescent MTs; $a, b$ insert, $d, m 2$ and $o$ show fluorescent DNA as a result of BrdU incorporation, or labelling with DAPI or PI. $e, l, o$ show fluorescent cellulose as a result of labelling with Calcofluor White. $h$ shows starch grains as a result of labelling I/KI. $c, g, k, n$ show fluorescent mitochondria and ER as a result of labelling with $\mathrm{DiOC}_{6}$. (a) Microspore-derived structure with six labelled nuclei. Labelling in all cells might indicate synchronous S-phase. Visualization of DNA synthesis by BrdU incorporation and immunocytochemical labelling with Alexa 488 (green) indicating that all nuclei had incorporated BrdU as a result of DNA synthesis during the pulse labelling. (b) Structure with a dense network of CMTs (green) without preferential orientation, close to the enclosing exine. Insert shows six round nuclei after PI staining (red). (c) Multicellular type I embryo with DiOC $_{6}$-stained mitochondria and ER in the peripheral cytoplasm of cells. (d) 8-Nucleate structure on the fourth day of culture. Structure still enclosed in the exine observed in UV after DAPI staining. (e) Multicellular ELS stained with Calcofluor White observed with UV showing cellulose cell walls (blue) of the outer cells. Insert shows the same structure which is partly released from the exine. $(f)$ Globular ELS on the seventh day of culture. ELS with mitotic spindle (arrow), phragmoplast and CMTs close to the plasma membrane of the outer cells. Insert shows the place of exine attachment in DIC. $(g)$ Globular ELS with DiOC $_{6}$-stained mitochondria and ER in the peripheral cytoplasm of the outer cells. Insert shows the place of exine attachment in DIC. (h) ELS with starch grains after I/KI staining observed in DIC. Some cells accumulate starch grains at one pole. (i) Phragmoplasts and CMTs without preferential orientation in the outer cells of globular ELS, which released from the exine. $(j-l)$ Globular ELSs at dermatogen stage with exine remnants at one pole. $(j)$ Pattern of CMTs in protoderm cells. Insert shows the same structure in DIC. $(k)$ Mitochondria and ER after $\mathrm{DiOC}_{6}$ staining in the peripheral cytoplasm of the outer cells. ( $l$ ) Cellulose deposits in the outer cells after Calcofluor White labelling. Insert shows the same structure in DIC. ( $m-$ o) Multi-cellular ELS released from the exine showing two domains. ( $m 1)$ Phragmoplasts and cortical MTs are only intensively labelled in the domain with the small cells. $(m 2)$ The small isodiametric cells exhibit intensively labelled nuclei after PI staining. The bigger cells show numerous small vacuoles and faint labelling of their nuclei. Insert shows the same structure in DIC. ( $n$ ) The small isodiametric cells exhibit intensively labelled mitochondria and $\mathrm{ER}$ after $\mathrm{DiOC}_{6}$ staining. (o) The small isodiametric cells exhibit labelled cellulose deposits after Calcofluor White staining. Bar $=20 \mu \mathrm{m}$ 
Fig. 3 SEM observations of the surface of Brassica napus androgenic ELS. (a) Low magnification overview of ELS partly released from the exine. (b) Detail of $a$ with membranous ECM-like layer $(m)$ covering the surface of the early globular ELS cells. Note the fibrillar structures (arrows) forming a network between cells of the embryo. (b1) Magnification of details in $b$ with thinner and thicker fibrils. $(c, d)$ Globular embryo. (c) Overview and $(d)$ higher magnification of details in $c$. A fibrillar network over the surface is absent. Bars $=10 \mathrm{~nm}(b l), 10 \mu \mathrm{m}(c)$ and $50 \mu \mathrm{m}(a, b, d)$
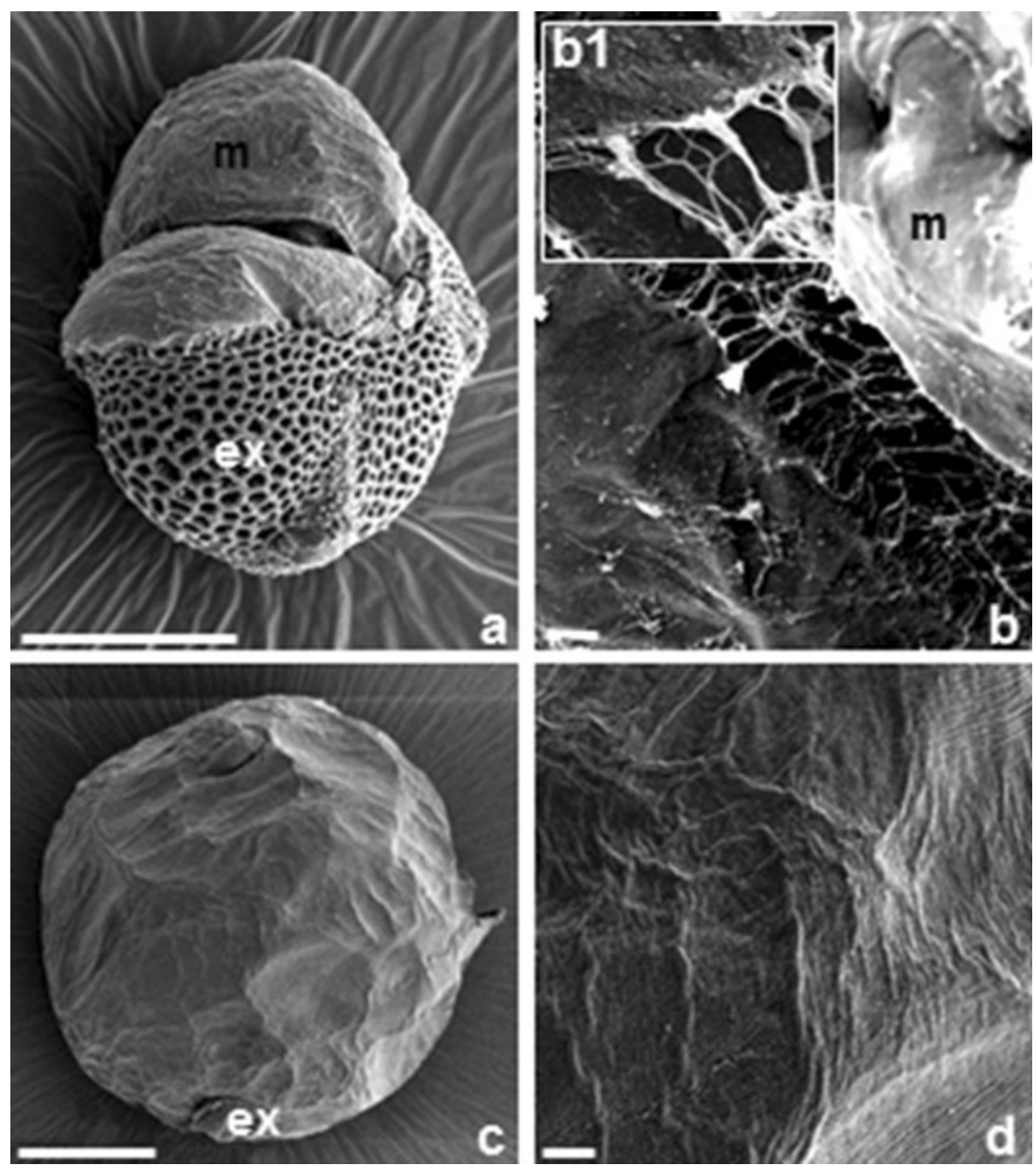

preferential orientation (Fig. 1, f). Contrary, in two-celled embryos of type II, multiple long MTs in parallel arrays and parallel to the cell wall were found at the equatorial plane of cell division (Fig. 1, h).

Symmetric nuclear division produced two equally condensed daughter nuclei (Fig. 1, h, i insert) with a well visible nucleolus in each of them (Fig. 1, h insert). Arrays of MTs formed a ring-shaped phragmoplast configuration (Fig. 1, h and Online Resource 2). Mitochondria and ER gave strong fluorescence after $\mathrm{DiOC}_{6}$ staining in the peripheral cytoplasm of both cells (Fig. 1, i). More divisions followed within a period of 3 days, resulting in three to four celled structures, of which the nuclei were still close to the original wall of the microspore (Fig. 1, k, l). In type I structures, mitochondria-ER gave strong fluorescence after $\mathrm{DiOC}_{6}$ staining in the vicinity of the nuclei and in the peripheral cytoplasm close to the sporoderm (Fig. 1, 1 insert). Calcofluor White staining did not reveal cellulose deposits. Fluorescence caused by the incorporation of BrdU, Alexa 488, PI and DAPI labelling demonstrated the absence (Fig. 1, j) or presence (Fig. 2, a) of synchronization of cell cycle in both types of embryos. In dividing structures (types I and II), BrdU got incorporated into DNA, as a result of DNA synthesis during the pulse labelling of $24 \mathrm{~h}$, when at least one of the ELS nuclei/cells was dividing. Alexa 488 marked MTs in mitotic spindles (types I and II) and phragmoplasts (only type II). The cortical surface cell layer of multicellular type I embryos was covered by a dense network of CMTs. These CMTs exhibited no preferential orientation (Fig. 2, b). Mitochondria and ER gave strong fluorescence after $\mathrm{DiOC}_{6}$ staining in the peripheral cytoplasm of the cells (Fig. 2, c). As a consequence of proceeding through the cell divisions in both types of embryos, the number of nuclei (types I and II) increased. On day 4 , there were structures with four to ten nuclei enclosed by the exine (Fig. 2, a-d).

Multicellular structures (derived from the types I and II embryos) emerged from the exine by day 5 . In these structures, Calcofluor White stained the cellulosic component of the newly synthesized cell walls. At about day 7, they showed features of globular embryos, which developed into heart stage embryos without suspensors in 9-10-days-old cultures (Fig. 2, e, e insert).

Anticlinal and periclinal cell divisions of the outer cells of globular types I and II ELSs resulted in the development of protoderm, sub-epidermal cells and the enlargement of the embryo, which typically was devoid of a suspensor (Fig. 2, 


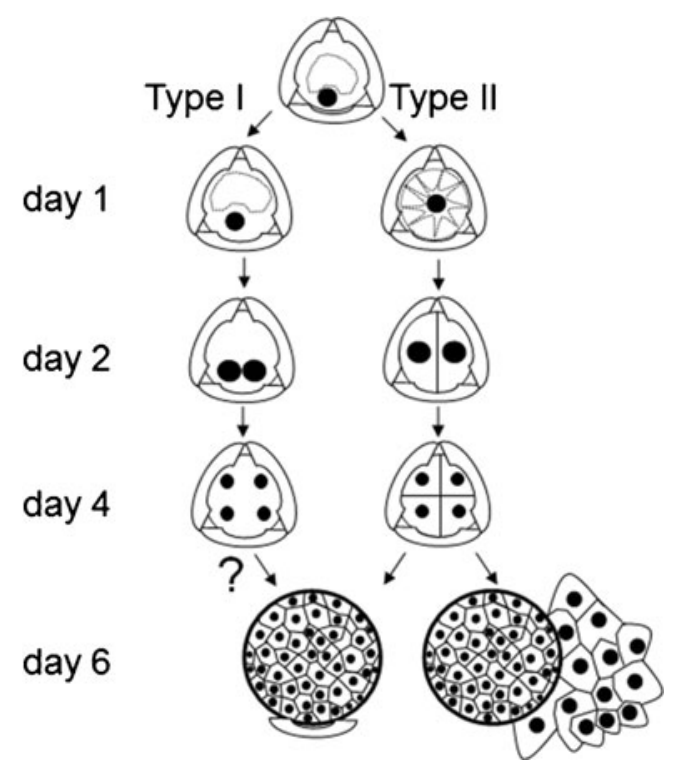

Fig. 4 Scheme of type I and type II B. napus microspore embryogenesis pathways. Type I embryos derive from microspores with their nucleus located close to the microspore cell wall. Type II embryos derive from microspores with a centrally located nucleus. Symmetrical divisions in types I and II structures lead to multicellular ELS formation. In type I embryogenesis, cellulose cell walls are not detected by Calcofluor White staining before day 6 of culture. Globular ELS with the exine remnant at the one pole. Two-domain ELSs released from the exine

e-1). There was again no overall net orientation of the CMTs during ELS development at the globular stage. Preprophase bands (PPBs), mitotic spindles, phragmoplasts and arrays of CMTs were regularly found in all cells of the ELSs (Fig. 2, f, $i, j)$. The frequent occurrence of these forms of MT arrays in many globular embryos indicated that the cells of the globular ELS divided intensively already within the exine. The unruptured globular structures finally consisted of a mass of relatively small cells. These structures did not exhibit differentiation in shape. Therefore, they were analyzed for the expression of internal polarity by visualizing the distribution of mitochondria and ER with $\mathrm{DiOC}_{6}$ and starch grains with $\mathrm{I} / \mathrm{KI}$. Mitochondria and ER gave strong fluorescence in the peripheral cytoplasm of all cells with cellulose deposits in the cell walls (Fig. 2, g, k-1). Cells that accumulated starch grains were only present at one pole of the ELS (Fig. 2, h). It has been observed at the stage of few cells in ELS that early exine rupturing resulted in the release of early ELS from the microspore cell wall, and those in ELS exhibited cell volume increase. The exine often remained attached to the structure at the only one pole, marking external polarity (Fig. 2, e-g, j1). Once ELSs had released from the exine, they sometimes had bigger cells between a mass of small cells (Fig. 2, m1, $\mathrm{m} 2$ ). The MT cytoskeleton was visible in all small cells, whereas no MTs were observed in the big cells (Fig. 2, m1, $\mathrm{m} 2$, insert). The big cells had higher vacuolization and fainter fluorescence of DNA in nuclei after PI labelling (Fig. 2, m2, insert), fainter fluorescence of mitochondria and ER after $\mathrm{DiOC}_{6}$ staining (Fig. 2, n) and fainter fluorescence of cellulose deposits (Fig. 2, o), while in the same cells, RNA in nucleoli resulted in intensive red fluorescence (Fig. 2, m2).

SEM analysis revealed that proembryos at the early globular stage show a compact fibrillar network on the surface of cells (Fig. 3, a) and between those cells forming net-like bridges (Fig. 3, b, b1 insert). Some of the fibrils were thicker, perhaps because they were linked to other fibrils forming bundles. This zfibrillar network of ECM-like structure was less apparent in mature embryos with differentiated protoderm cell layer at the late globular stage and further (Fig. 3, c, d).

\section{Discussion}

Microspore embryogenesis in a conventional microspore culture of $B$. napus under prolonged heat stress (5 days at $32{ }^{\circ} \mathrm{C}$ and then at $25{ }^{\circ} \mathrm{C}$ ) results in ELS formation without suspensor (Binarova et al. 1993; Hause et al. 1994; Custers et al. 1994; Cordewener et al. 1995).

Exposure of microspores to heat causes changes in the pathway of development from gametophytic to sporophytic. Sporophytic development in microspores is accompanied by swelling, autophagy of the cytoplasm, cytoskeletal and cytoplasmic rearrangement leading to changes in cell polarity, cell cycle, cell wall formation and gene expression (Zoriniants et al. 2005).

Male gametogenesis critically depends upon cell polarization, which contributes to a highly asymmetric cell division (PMI; first pollen mitosis). In microspores at the vacuolate stage, the nucleus is at the G1 phase and is located close to exine. Displacement continues throughout the mitotic cycle (Tanaka et al. 1979), and the polar position of the nucleus is maintained by the MT cytoskeleton (Tanaka et al. 1998; Dubas et al. 2012).

Similar to that, we have found that in some heat-induced microspores, the polar, eccentric position (type I) of the nucleus was maintained by the MT cytoskeleton. As a second result of our experiments, it was found that the nucleus remained located in the centre of the cell (type II), surrounded by cytoplasm strands in a 'star-like' morphology. Interestingly, microspores of rice (Raina and Irfan 1998), rapeseed (Zaki and Dickinson 1991), tobacco (Touraev et al. 1997), wheat (Indrianto et al. 2001) or triticale (Zur et al. 2008) also acquire a 'star-like' morphology. Stress might break a connection between the plasma membrane-actin-MT-nucleus complex and allow the nucleus to take a position at the centre of the cell (Pauls et al. 2006).

Because the majority of heat-treated microspores of $B$. napus exhibited nuclei remaining close to the exine (Hause et al. 1993), we suppose that in these microspores, the organization of MTs remained undisturbed. In such cases, 
the position of the nucleus within the microspore expresses the polar organization of the microspore from the beginning of microspore embryogenesis.

We also observed that despite this difference in the expression of polarity, the nucleus entered S-phase, the mitotic spindle changed orientation and symmetric division occurred in both types of microspores (types I and II). Finally, two daughter nuclei of similar size were observed within the microspore parental wall (Zaki and Dickinson 1990; Telmer et al. 1992, 1995). Successive mitotic divisions led to the formation of multicellular or multinucleate structures from types I and II microspores, respectively. However, to clarify these observations, tracking of the entire process of embryogenesis from single selected microspores throughout the whole culture period should be performed. In case of types I and II microspores, embryogenesis proceeded in the wellknown, classical pathway (Zaki and Dickinson 1991; Hause et al. 1993; Custers et al. 1994). Contrary to our results, Zaki and Dickinson (1991) noticed that the majority of ELS derived from the type II microspores.

Previous investigations in B. napus and triticale microspore cultures indicated that changes in the MT organization during the embryogenesis induction would lead to appearance of a preprophase band (PPB), which might determine division symmetry (Simmonds 1994; Simmonds and Keller 1999; Dubas et al. 2010, 2011).

We confirmed that microspores, induced to androgenesis, underwent cell divisions with the change of division plane (Simmonds 1994; Simmonds and Keller 1999), but were not able to monitor PPB formation at this stage. Changes in the MT cytoskeleton configuration clearly coincided with successive nuclear divisions, which led finally to multicellular ELSs formation (Simmonds and Keller 1999; Dubas et al. 2010).

MTs and actin filaments, the two key components of the plant cytoskeleton, play an essential role in cell wall formation and for cell-to-cell communication through plasmodesmata, which coordinate cellular behaviour (McLean et al. 1997). Staining with Calcofluor White revealed newly formed cellulose cell walls, while immunodetection of MTs revealed MTs close to the plasma membranes of multicellular ELS. Based on the observations of places of cellulose formation and MTs occurrence, MTs close to the cell membranes might function in cellulose microfibril deposition in the new cell walls (Vesk et al. 1996; Kost et al. 2002). MTs are known to predict the location of secondary wall deposition and influence the spatial arrangement of newly synthesized cellulose microfibrils (Cyr 1994).

In type I embryos, cellulose deposition in cell walls could not be detected after Calcofluor White staining. We assume the primary cell wall of ELS's cells was poorly developed, or in vitro conditions with the heat treatment affected cellulose synthesis (Sato et al. 2001) or cellulose synthase upregulation (Pauls et al. 2006). Apparently, multinucleate structures existed in suspension culture for a certain period of time. However, the question about the failure of deposition of cell wall matrix polysaccharide components in the new developing cell plates has no clear answer. It could be that the cellulose is not present in ELSs cells, but the pectic middle lamella is present, and it cements the cell walls of two adjoining cells together in ELS before the bursting of the exine happens.

When the exine was broken, new cell wall formation was initiated in ELS. Finally, multicellular structures at the globular stage were found in suspension.

We have noticed that polarity in multicellular structures was expressed by the accumulation of starch grains in a specific region, marking the future root pole. Similar finding was reported previously by Hause et al. (1994) in Brassica. In microspore-derived embryos of wheat, starch granules accumulated in a zone opposite to the place of exine rapture (Indrianto et al. 2001).

Our results show that the distribution of ER, mitochondria and starch grains coincided with the specific arrangements of the MT cytoskeleton, or could maintain cell polarity at some stages of microspore embryogenesis. It is known that in mammals ER, mitochondria exploit cytoskeletal elements as tracks for their directional movements by using a specialized molecular machinery (Anesti and Scorrano 2006). In plants, actin filaments function as such.

In addition, the polarity of ELSs was also expressed by the size of cells, their vacuolization, MT assembly and intensity of labelling of nuclei after PI staining. These facts illustrate the presence of two types of ELS with two different domains in suspension culture. Evidence for MT involvement in cell polarity development and maintenance during plant cell morphogenesis, especially in trichome formation, is mounting (Smith and Oppenheimer 2005).

A similar phenomenon of the presence of two-domain structures in maize microspore-derived embryos was observed by Testillano et al. (2002). One domain contained cells with one nucleus, a compact nucleolus, dense cytoplasm with abundant ribosomes, ER, plastids, mitochondria and other organelles. The ultrastructural organization of large cells was quite different having one or more big nuclei, numerous and large vacuoles, few ribosomes and big plastids, among them numerous amyloplasts. Both domains differed also in the intensity of anti- $\beta$ tubulin signal. Twodomain embryos attributed only to monocots microspore embryogenesis so far.

The significance of the presence of a fibrillar ECM-like structure on the surface of few-celled early proembryo that is releasing from the exine is unclear. Is this structure really associated with embryogenic competence and could it be an early structural marker for polar growth of spring oilseed rape microspore embryos? To test this hypothesis, additional studies on the ultrastructural levels should be performed. Physical state and local mechanical properties of the ECM 
were described in animal and plant multicellular organisms (Baluška et al. 2003). The ECM was considered as required to attain a polar shape. ECM was discovered in different types of in vitro cultures of different species, mainly in those where embryo formation was induced (Dubois et al. 1992; Šamaj et al. 1995; Namasivayam et al. 2006; PopielarskaKonieczna et al. 2010). So far, no ECM-like structure was found in direct androgenic cultures of any specimen. Moreover, for the first time, we show that the polarity of embryos was expressed by the appearance of ECM-like structure at the place where the exine was broken, playing probably a crucial role in cell adhesion, communication and integration during further embryo development.

Acknowledgements We thank Mr A. van Aelst (Wageningen University and Research Centre) for his kind help with sample preparation and scanning electron microscopy. CLSM's work was done in the frame of a fellowship at Wageningen University \& Plant Research International, the Netherlands within CropStress project QLK5-CT-200230424 of IPP PAS and individual STMS of COST 851.

Conflicts of interest The authors declare that they have no conflict of interest.

Open Access This article is distributed under the terms of the Creative Commons Attribution License which permits any use, distribution, and reproduction in any medium, provided the original author(s) and the source are credited.

\section{References}

Anesti V, Scorrano L (2006) The relationship between mitochondrial shape and function and the cytoskeleton. Biochim Biophys Acta 1757:692-699

Baluška F, Šamaj J, Wojtaszek P, Volkmann D, Menzel D (2003) Cytoskeleton-plasma membrane-cell wall continuum in plants. Emerging links revisited. Plant Physiol 133:482-491

Benziman M, Haigler CH, Brown RM, White AR, Cooper KM (1980) Cellulose biogenesis. Polymerization and crystallization are coupled processes in Acetobacter xylinum. Proc Natl Acad Sci USA 77:6678-6682

Berthiaume F, Moghe PV, Toner M, Yarmush ML (1996) Effect of extracellular matrix topology on cell structure, function, and physiological responsiveness: hepatocytes cultured in a sandwich configuration. FASEB J 10:1471-1484

Binarova P, Straatman K, Hause B, Hause G, van Lammeren AAM (1993) Nuclear DNA synthesis during the induction of embryogenesis in cultured microspores and pollen of Brassica napus L. TAG 87:9-16

Binarova P, Hause G, Cenklová V, Cordewener JHG, van Lookeren Campagne MM (1997) A short severe heat shock is required to induce embryogenesis in late bicellular pollen of Brassica napus L. Sex. Plant Reprod 10:200-208

Boutilier K, Offringa R, Sharma VK, Kieft H, Ouellet T, Zhang L, Hattori J, Liu CM, van Lammeren AA, Miki BL, Custers JB, van Lookeren Campagne MM (2002) Ectopic expression of BABY BOOM triggers a conversion from vegetative to embryonic growth. Plant Cell 14(8):1737-49

Cordewener HG, Hause G, Görgen E, Busink R, Hause B, Dons HJM, van Lammeren AAM, van Lookeren Campagne MM, Pechan P (1995)
Changes in synthesis and localization of members of the $70-\mathrm{kDa}$ class of heat shock proteins accompany the induction of embryogenesis in Brassica napus L. microspores. Planta 196:747-755

Cordewener J, Bergervoet J, Liu CM (2000) Changes in protein synthesis and phosphorylation during microspore embryogenesis in Brassica napus. J Plant Physiol 156:156-163

Custers JBM, Cordewener JHG, Nöllen Y, Dons HJM, van Lookeren Campagne MM (1994) Temperature controls both gametophytic and sporophytic development in microspore culture of Brassica napus. Plant Cell Rep 13:267-271

Custers JBM, Cordewener JHG, Fiers MA, Massen BTH, van Lookeren Campagne MM, Liu CM (2001) Androgenesis in Brassica. A model system to study the initiation of plant embryogenesis. In: Bhojwani SS, Soh WY (eds) Current trends in the embryology of angiosperms. Kluwer, The Netherlands, pp 451-470

Custers JBM (2003) Microspore culture in rapeseed (Brassica napus L.). In: Maluszynski M, Kasha KJ, Forster BP, Szarejko I (eds) Doubled haploid production in crop plants - the manual. Kluwer Academic, Dordrecht, pp 185-194

Cyr RJ (1994) Microtubules in plant morphogenesis: role of the cortical array. Annu Rev Cell Biol 10:153-180

Dubas E, Wędzony M, Petrovska B, Salaj J, Żur I (2010) Cell structural reorganization during induction of androgenesis in isolated microspore cultures of triticale (x Triticosecale Wittm.). Acta Biol Cracov Bot 52(1):73-86

Dubas E, Custers J, Kieft H, Wędzony M, van Lammeren AAM (2011) Microtubule configurations and nuclear DNA synthesis during initiation of suspensor-bearing embryos from Brassica napus cv. Topas microspores. Plant Cell Rep 30:2105-2116

Dubas E, Wędzony M, Custers J, Kieft H, van Lammeren AAM (2012) Gametophytic development of Brassica napus pollen in vitro enables examination of cytoskeleton and nuclear movements. Protoplasma 249(2):369-377

Dubois T, Dubois J, Guedira M, Diop A, Vasseur J (1992) SEM Characterization of an extracellular matrix around somatic proembryos in roots of Cichorium. Ann Bot 70(2):119-124

Ferrie A (2003) Microspore culture of Brassica species. In: Maluszynski M, Kasha KJ, Forster BP, Szarejko I (eds) Doubled haploid production in crop plant- the manual. Kluwer Academic, Dordrecht, pp 205-215

Forster BP, Heberle-Bors E, Kasha KJ, Touraev A (2007) The resurgence of haploids in higher plants. Trends Plant Sci 12:368-375

Friml J, Benkova E, Mayer U, Palme K, Muster G (2003) Automated whole mount localisation techniques for plant seedlings. Plant $\mathrm{J}$ $34(1): 115-124$

Gervais C, Newcomb W, Simmonds DH (2000) Rearrangement of the actin filament and microtubule cytoskeleton during induction of microspore embryogenesis in Brasssica napus L. cv. Topas. Protoplasma 213:194-202

Hause G, Hause B, van Lammeren AAM (1992) Microtubular and actin filament configurations during microspore and pollen development in Brassica napus cv. Topas. Can J Bot 70:1369-1376

Hause B, Hause G, Pechan P, van Lammeren AAM (1993) Cytoskeletal changes and induction of embryogenesis in microspore and pollen cultures of Brassica napus L. Cell Biol Int 17(2):153-168

Hause B, van Veenendaal WLH, Hause G, van Lammeren AAM (1994) Expression of polarity during early development of microsporederived and zygotic embryos of Brassica napus L. cv. Topas. Bot Acta 107(6):407-415

Hosp J, Tashpulatov A, Roessner U, Barsova E, Katholnigg H, Steinborn R, Melikant B, Lukyanov S, Heberle-Bors E, Touraev A (2007) Transcriptional and metabolic profiles of stress-induced, embryogenic tobacco microspores. Plant Mol Biol 63:137-149

Indrianto A, Barinova I, Touraev A, Heberle-Bors E (2001) Tracking individual wheat pollen in vitro: identification of embryogenic pollen and body axis formation in the embryo. Planta 212:163-174 
Joosen R, Cordewener J, Supena EDJ, Vorst O, Lammers M, Maliepaard C, Zeilmaker T, Miki B, America T, Custers J, Boutilier K (2007) Combined transcriptome and proteome analysis identifies pathways and robust markers associated with the establishment of Brassica napus microspore-derived embryo development. Plant Physiol 144:155-172

Kost B, Bao Y-Q, Chua N-H (2002) Cytoskeleton and plant organogenesis. Phil Trans R Soc Lond B Biol Sci 357:777-789

Lichter R (1982) Induction of haploid plants from isolated pollen of Brassica napus. Z Pflanzenphysiol 105:427-434Malik MR, Wang F, Dirpaul JM, Zhou N, Hammerlindl J, Keller W, Abrams SR, Ferrie AMR, Krochko JE (2008) Isolation of an embryogenic line from non-embryogenic Brassica napus cv. Westar through microscope embryogenesis. J Exp Bot 59:2857-2873

McLean BG, Hempel FD, Zambryski PC (1997) Plant intercellular communication via plasmodesmata. Plant Cell 9:1043-1054Namasivayam P, Skepper J, Hanke D (2006) Identification of a potential structural marker for embryogenic competency in the Brassica napus ssp. oleifera embryogenic tissue. Plant Cell Rep 25(9):887-895

Pauls KP, Chan J, Woronuk G, Schulze D, Brazolot J (2006) When microspores decide to become embryos-cellular and molecular changes. Can J Bot 84:668-678

Pechan PM, Keller WA (1988) Identification of potentially embryogenic microspores in Brassica napus. Physiol Plant 74:377-384

Popielarska-Konieczna M, Bohdanowicz J, Starnawska E (2010) Extracellular matrix of plant callus tissue visualized by ESEM and SEM. Protoplasma 247:121-125

Raina SK, Irfan ST (1998) High frequency embryogenesis and plantlet regeneration from isolated microspores of indica rice. Plant Cell Rep 17:957-962Šamaj J, Bobfik M, Blehová A, Krištin J, Auxtovfá-Šamajová O (1995) Developmental SEM observations on an extracellular matrix in embryogenic calli of Drosera rotundifolia and Zea mays. Protoplasma 186:45-49

Sato S, Kato T, Kakegawa K, Ishii T, Liu YG, Awano T, Takabe K, Nishiyama Y, Kuga S, Sato S, Nakamura Y, Tabata S, Shibata D (2001) Role of the putative membrane-bound endo-1,4- $\beta$ glucanase KORRIGAN in cell elongation and cellulose synthesis in Arabidopsis thaliana. Plant Cell Physiol 42(3):251-263

Seguí-Simarro JM, Nuez F (2008) How microspores transform into haploid embryos: changes associated with embryogenesis induction and microspore derived embryogenesis. Physiol Plantarum 134:1-12

Simmonds DH (1994) Mechanism of induction of microspore embryogenesis in Brassica napus; significance of the PPBs of microtubules in the first sporophytic division. In: Akkas $\mathrm{N}$ (ed) Biomechanics of active movement and division of cells. Springer, Berlin, pp 569-574, NATO ASI series, H 84

Simmonds DH, Keller WA (1999) Significance of preprophase bands in induction of embryogenesis from microspores of Brassica napus. Planta 208:383-391

Smith LG, Oppenheimer DG (2005) Spatial control of cell expansion by the plant cytoskeleton. Annu Rev Cell Dev Biol 21:271-295

Smýkal P (2000) Pollen embryogenesis - the stress mediated switch from gametophytic to sporophytic development. Current status and future prospects. Biol Plantarum 43(4):481-489

Supena EDJ, Winarto B, Riksen T, Dubas E, van Lammeren A, Offringa R, Boutilier K, Custers J (2008) Regeneration of zygotic-like microspore-derived embryos suggests an important role for the suspensor in early embryo patterning. J ExpBot 59(4):803-814

Tanaka I, Taguchi T, Ito M (1979) Studies on microspore development in liliaceous plants. I. The duration of the cell cycle and developmental aspects in lily microspores. Bot Mag Tokyo 92:291-298

Tanaka I, Ono K, Fukuda T (1998) The developmental fate of angiosperm pollen is associated with a preferential decrease in the level of histone H1 in the vegetative nucleus. Planta 206:561-569

Tang X, Liu Y, He Y, Ma L, Sun MX (2013) Exine dehiscing induces rape microspore polarity, which results in different daughter cell fate and fixes the apical-basal axis of the embryo. J Exp Bot 64:215-228

Telmer CA, Simmonds DH, Newcomb W (1992) Determination of developmental stage to obtain high frequencies of embryogenic microspores in Brassica napus. Physiol Plant 84:417-424

Telmer CA, Newcomb W, Simmonds DH (1995) Cellular changes during heat shock induction and embryo development of cultured microspores of Brassica napus cv. Topas. Protoplasma 185:106-112

Terasaki M (1994) Labeling of endoplasmic reticulum with $\operatorname{DiOC}_{6}(3)$. In: Celis J (ed) Cell biology: a laboratory handbook. Academic, Orlando, pp 381-386

Testillano PS, Ramírez C, Domenech J, Coronado MJ, Vergne P, Matthys-Rochon E, Risueño M (2002) Young microspore-derived maize embryos show two domains with defined features also present in zygotic embryogenesis. Int J Dev Biol 46:1035-1047

Touraev A, Vicente O, Heberle-Bors E (1997) Initiation of microspore embryogenesis by stress. Trends Plant Sci 2:285-303

Vesk PA, Vesk M, Gunning BES (1996) Field emission scanning electron microscopy of microtubule arrays in plant cells. Protoplasma 195:168-182

Wasteneys GO, Galway ME (2003) Remodeling the cytoskeleton for growth and form: an overview with some new views. Ann Rev of Plant Biol 54:691-722

Wędzony M, Forster BP, Żur I, Golemiec E, Szechyńska-Hebda M, Dubas E, Gołębiowska G (2009) Progress in doubled haploid technology in higher plants. In: Touraev A, Jain M, Forster B (eds) Advances in haploid production in higher plants. Springer, Heidelberg, pp 1-35

Wędzony M, Szechyńska-Hebda M, Żur I, Dubas E, Krzewska M (2013) Tissue culture and regeneration: a prerequisite for alien gene transfer. In: Pratap A, Kumar J (eds) Alien gene transfer in crop plants, Vol. I. Innovations, methods and risk assessment. Indian Institute of Pulses Research, Kanpur, p 364

Zaki MAM, Dickinson HG (1990) Structural changes during the first divisions of embryos resulting, from anther and free microspore culture in Brassica napus. Protoplasma 156:149-162

Zaki MAM, Dickinson HG (1991) Microspore-derived embryos in Brassica: the significance of division symmetry in pollen mitosis to embryogenic development. Sex Plant Reprod 4:48-55

Zoriniants S, Tashpulatov AS, Heberle-Bors E, Touraev A (2005) The role of stress in the induction of haploid microspore embryogenesis. In: Palmer CE, Keller WA, Kasha KJ (eds) Haploids in crop improvement II: biotechnology in agriculture and forestry, vol 56. Springer, Berlin, pp 35-52

Zur I, Dubas E, Golemiec E, Szechyńska-Hebda M, Janowiak F, Wędzony M (2008) Stress-induced changes important for effective androgenic induction in isolated microspore culture of triticale ( $\times$ Triticosecale Wittm.). Plant Cell Tiss Org 94:319-328 